\title{
Study on Spatial \&Temporal distribution and changes of Malaria disease in Andhra Pradesh, India.
}

\author{
${ }^{(1)}$ A.Raju, Resarch scholor, ${ }^{(2)}$ Prof. T.V.Krishna \\ Department of Geography, Andhra University, Visakhapanam, (AP). \\ DOI: 10.29322/IJSRP.11.11.2021.p11935 \\ http://dx.doi.org/10.29322/IJSRP.11.11.2021.p11935
}

\begin{abstract}
Among vector born diseases, malaria is a wide spread disease and causing highest morbidity and mortality rates over all continents. According to WHO in 2016, about 216 million people were infected and 4,45,000 deaths were reported in the world. $90 \%$ of the malaria cases reported in Africa only. India's physiographic, climatic and thick drainage system are favorable for the growth and distribution of malaria disease. Further India is having large population i.e human host with high density is also favorable condition for growth distribution of malaria disease. Malaria is endemic to Andhra Pradesh for over several decades. Further, there are no proper vector-control strategies that have led to a significant increase in the disease burden and are inadequate to prevent. In this context Andhra Pradesh is taken for the present study. Year wise data on Malaria Cases was collected for the 13 districts of Andhra Pradesh (2010-2019) to investigate Malaria outbreaks. Further, the study will find out high risk malaria Districts in Andhra Pradesh.
\end{abstract}

Index Terms- Parasite, Spatial, Temporal, North coastal Andhra, Central coastal Andhra and Rayalaseema.

\section{INTRODUCTION}

$\mathrm{M}$ alaria disease is widespread in Tropical and sub- tropical regions around the equator, including sub - Africa and Asia. According to WHO, India contributes $77 \%$ of the total malaria cases in S.E. Asia. The female Anopheles mosquito which feeds on human blood plays the role of a vector in transmitting the parasite and incidence of malaria. Where higher the humidity there higher cases of malaria reported. Human malaria can be caused by different species of plasmodium parasite. P. falciparum (P.f) and P. vivax (P.v) are the most important, accounting for more than 95\% of cases worldwide.Malaria imposes great socio-economic burden on humanity, and with six other disease (diarrhea, HIV/AIDS, tuberculosis, measles, hepatitis, B, and pneumonia), accounts for $85 \%$ of global infectious disease burden. In India the malaria disease occurs throughout the year access the country. Malaria is public health problem in several parts of India. Further, malaria disease more prevalent during and after the rainy season due to mosquito. In India, the epidemiology of malaria is complex because of geo-ecological diversity, multi-ethnicity, and wide distribution of nine anopheline vectors transmitting three plasmodia species: P.flaciparum, P.vivax, and P.malaria. Anopheles culicifacies is widely distributed and is the principal vector of rural malaria, An.Stephensi is the primary urban vector, An.Fluviatilis is a vector in the hills and foothills, and An.minimus, An. nivipes, An.philippenen-sis, and An.dirus are vector in the northeast and An.sun- daicus is restricted to Andaman and Car Nicobar islands. An. annularis and An. Varuna is secondary vector with wide distribution. Incidence of malaria in different states of India is more prevalent in Rajasthan, Gujarat, Karnataka, Goa, southern Madhya Pradesh, Chhattisgarh, Jharkhand, and Orissa and northeastern states. India contributes 61 percent of malaria cases and 41 percent of malaria deaths in SEAR countries. Climate factor such as temperature, humidity and rainfall play an important role in the spread of malaria. The most dangerous areas are forest, forest margin, foothills, river belts, and mountain and river valleys. Climatic factors such as temperature, humidity and rainfall play an important role in the spread of malaria. The most dangerous areas are forest, forest margin, foothills, river belts, mountains and river valleys.. People in India mostly live in remote and inaccessible areas due to the usual geological conditions due to forests, mountains, valleys and perennial streams.

\section{OBJECTIVES:}

- To study temporal distribution and changes of Malaria cases.

- To examine the spatial distribution and changes of Malaria cases.

\section{Data base And Methodology:}

The study mostly depends upon secondary data and it was collected from the District Medical and Health Officer (DM\&HO) of 13 districts of Andhra Pradesh, and District Malaria Controlling Offices and also from Primary healthcare centers (PHC) regarding number of Malaria cases from 2010 to 2019 period of 13 districts of Andhra Pradesh. In this study, SPSS has been used for descriptive analysis and GIS for generating maps for the spatial study.

\section{Study area:}

Andhra Pradesh (Fig no.1), is one of the States of India lies on the eastern boarder of the Peninsular India and extends from $12^{\circ} 45^{\prime}$ to $19^{\circ} 50^{\prime} \mathrm{N}$ latitudes and $76^{\circ} 45^{\prime}$ to $84^{\circ} 45^{\prime}$ E longitudes. 


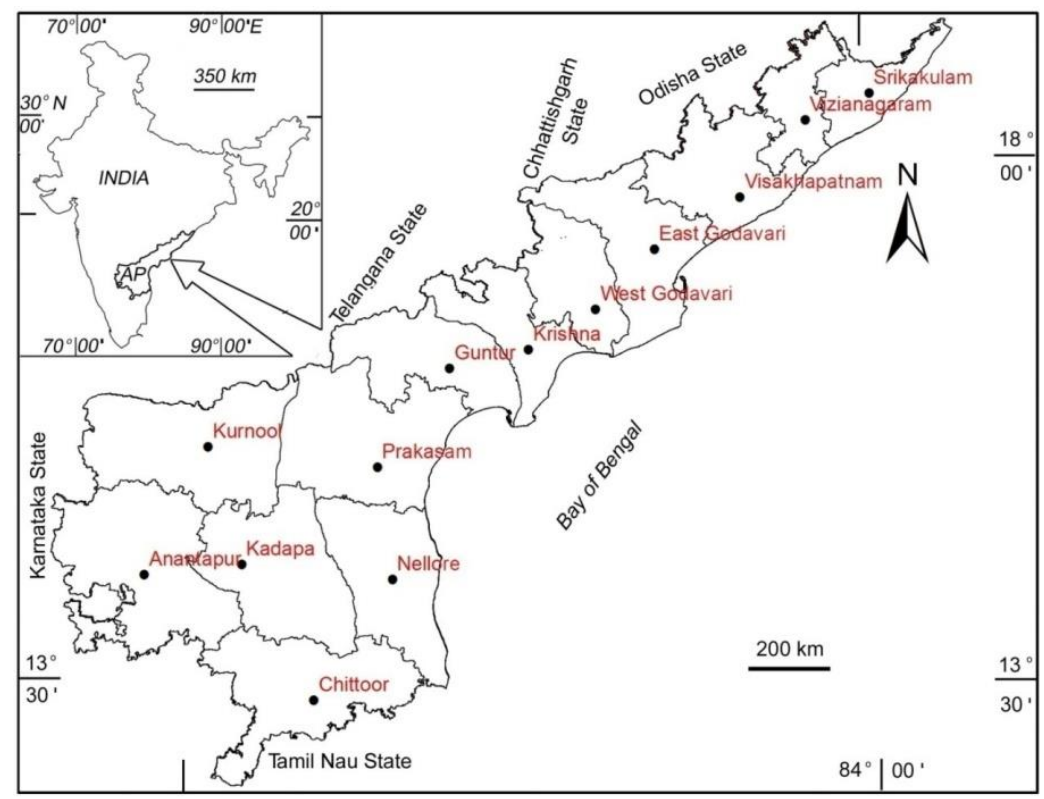

Fig no1. Location map of the Study area

The study area (AP) is bordered by Odisha and Chhattisgarh in the north, Telangana and Karnataka in the west, Tamil Nadu in the south and Bay of Bengal in the east. The State is the eighth largest State in terms of geographical area which occupies 160,200 $\mathrm{Km} 2$ which forms $5.13 \%$ of the landmass of the country. The State has second longest coastline of $974 \mathrm{~km}$ among all the states. Andhra Pradesh contains thirteen districts with three physiographic regions. The north coastal Andhra region contains three districts namely Srikakulam, Vizianagaram, Visakhapatnam. The central coastal Andhra region contains six districts namely East Godavari, West Godavari, Krishna, Guntur, Prakasam and
Nellore and Rayalaseema region contains four districts namely Anantapur, Kurnool, Kadapa and Chittoor . According to 2011 census, Andhra Pradesh ranks ten with respect to population of 49.6 million which accounts $4.08 \%$ of Country's population of which 24.7 million are male and 24.6 female population. The density of population is about 308 persons /sq kilometer.

\section{RESULTS AND DISCUSSIONS:}

4.1 Distribution of malaria cases during 2010 - 2019 period in the Study area

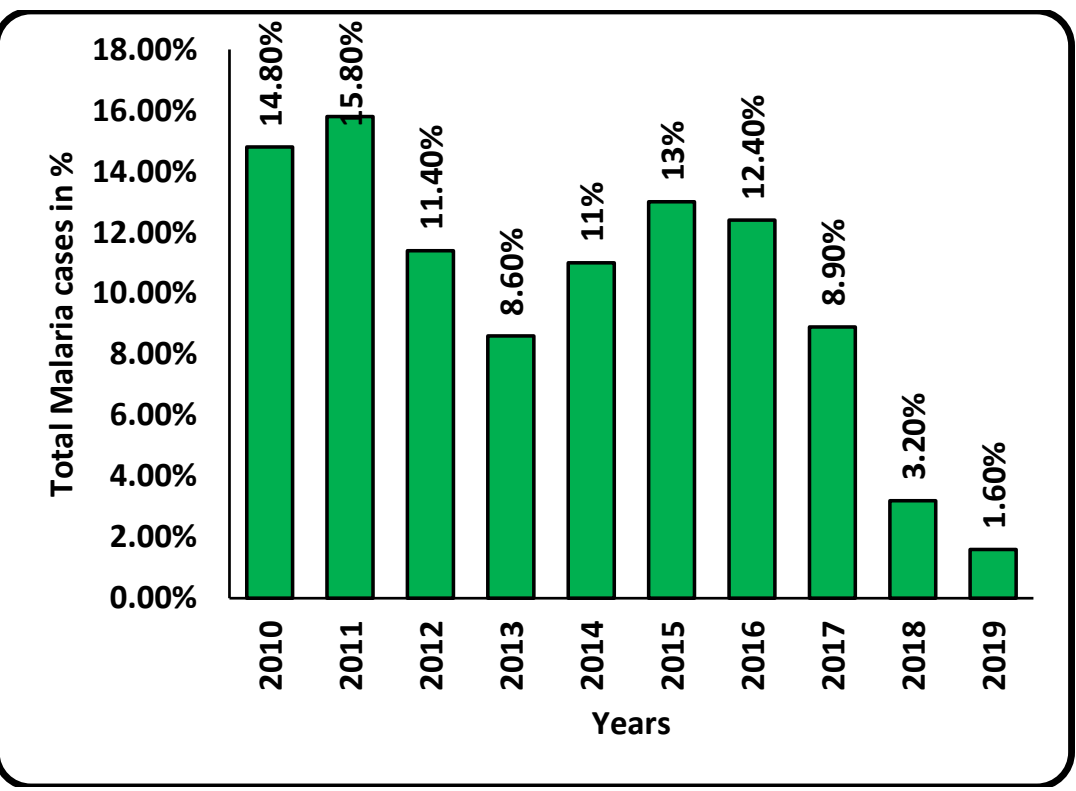

Fig no: 2 Distributions of malaria cases during 2010 - 2019 periods in the study area.

It can be observed from the fig no: 2 that about, $1,90,895$ malaria cases recorded during 2010 - 2019 period in the study region. Highest number of malaria cases recorded in 2011 year
(30,199 cases) followed by 2010 ( 26,725 cases), $2015(25,042$ cases), 2016 (23,613 cases), 2012 (21,772 cases), 2014 ( 21,077 cases), 2017 (16,972 cases), 2013 (16,351 cases), 2018 (6040 
cases) and 2019 (3104 cases). Regarding the distribution of malaria cases according to regions highest about $47.7 \%$ of the total cases recorded in north coastal Andhra region followed by
Rayalaseema region $(34.3 \%)$ and low number of cases recorded in central costal Andhra region (10\%).

Table no.1- Changes in Malaria cases during 2010 - 2019 period in the study area.

\begin{tabular}{|c|c|c|c|c|}
\hline \multirow[t]{2}{*}{ S. No. } & \multirow[t]{2}{*}{ Name Of the District } & \multicolumn{2}{|l|}{ Cases during } & \multirow[t]{2}{*}{$\begin{array}{l}\text { Change in Cases } \\
(\%)\end{array}$} \\
\hline & & $2010-2014$ & $2015-2019$ & \\
\hline & \multicolumn{4}{|c|}{ North coastal Andhra region } \\
\hline 1 & Srikakulam & $7150(6.1)$ & $2817(3.7)$ & $-4333(60.60 \%)$ \\
\hline 2 & Vzianagaram & $18423(15.8)$ & $8444(11.2)$ & $-9979(54.1 \%)$ \\
\hline \multirow[t]{3}{*}{3} & Visakhapatnam & $43626(37.5)$ & $24885(33.2)$ & $-18741(43 \%)$ \\
\hline & Sub Total & $69199(59.5)$ & $36146(48.3)$ & $-33053(47.7 \%)$ \\
\hline & \multicolumn{4}{|c|}{ Central Coastal Andhra region } \\
\hline 4 & East Godavari & $18630(16.0)$ & $24373(32.5)$ & $+5743(30.8 \%)$ \\
\hline 5 & West Godavari & $3680(3.1)$ & $2270(3.0)$ & $-1410(38.3 \%)$ \\
\hline 6 & Krishna & $7685(6.6)$ & $1939(2.5)$ & $-5746(74.7 \%)$ \\
\hline 7 & Guntur & $2374(2.0)$ & $2785(3.7)$ & $+411(17.3 \%)$ \\
\hline 8 & Prakasam & $5482(4.7)$ & $1245(1.6)$ & $-4237(77.2 \%)$ \\
\hline \multirow[t]{3}{*}{9} & $\begin{array}{l}\text { Nellore/ } \\
\text { Pottisriramulu district }\end{array}$ & $741(0.6)$ & $541(0.7)$ & $-200(26.9 \%)$ \\
\hline & Sub Total & $38592(33.2)$ & $33153(44.3)$ & $-5439(10.0 \%)$ \\
\hline & \multicolumn{4}{|l|}{ Rayalaseema region } \\
\hline 10 & Chittoor & $1100(0.9)$ & $354(0.4)$ & $-746(67.8 \%)$ \\
\hline 11 & YSR Kadapa & $4136(3.5)$ & $2030(2.7)$ & $-2106(50.9 \%)$ \\
\hline 12 & Anantapur & $2015(1.7)$ & $2072(2.7)$ & $-57 \quad(-2.8 \%)$ \\
\hline \multirow[t]{3}{*}{13} & Kurnool & $1082(0.9)$ & $1016(1.3)$ & $-66 \quad(6.0 \%)$ \\
\hline & Sub Total & $8333(7.1)$ & $5472(7.3)$ & $-2861(34.3 \%)$ \\
\hline & Grand Total & $\mathbf{1 , 1 6 , 1 2 4}(100 \%)$ & $\mathbf{7 4 , 7 7 1}(100 \%)$ & $-\mathbf{4 1 , 3 5 3}(35.6 \%)$ \\
\hline
\end{tabular}

Source: Compiled by the author of respective districts

\section{2 (a) Temporal distribution of malaria cases during 2010 - 2014 period}

It can be observed from the table no: 1 , that about $1,16,124$ malaria cases recorded during 2010 - 2014 period in the study region(13 districts).Regarding changes in distribution of malaria cases according to districts, highest number of malaria cases about $43,626(37.5 \%)$ of the total cases recorded in Visakhapatnam district during $2010-2014$ period. Further, highest number of cases also recorded in 2010 (12,815 cases) followed by 2011 (8977 cases), 2014 (8410 cases), 2012 (7474 cases) and 2013 (5950).

East Godavari district recorded about 18,630 (16\%) cases during 2010 - 2014 period moreover highest number of malaria cases recorded in 2014 (5246 cases) about followed by 2011 (4760 cases), 2013 (3460 cases), 2012 (2750 cases) and 2010 (2414 cases) and showing increasing trend of malaria cases.

Vizianagaram district recorded about 18,423 (15.8\% cases) during $2010-2014$ period and highest number of cases recorded in 2011 (5449 cases) followed by 2012 (4992 cases), 2013 (2808 cases), 2014 (2778 cases) and 2010 (2396 cases) during decreasing trend in cases.

Krishna district recorded 7685 cases $(6.8 \%)$ of total cases and highest number of cases recorded in 2010 (2757 cases) followed by 2011 (2339 cases), 2012 (1585 cases), 2013 (592 cases) and 2014 (412 cases).

Srikakulam district recorded about 7,150 cases $(6.1 \%)$ of total cases and highest number of cases recorded in 2011 (2760 cases), followed by 2012 (1424 cases), 2010 (1289 cases), 2014 (903 cases), 2013 (774 cases), and showing decreasing trend in cases.

Prakasam district recorded about 5482 cases (4.7\%) of total cases and highest number of cases recorded in 2011 (1800 cases), followed by 2010 (1590 cases), 2012 (962 cases), 2013 (631 cases), 2014 (499 cases) showing decreasing trend in cases.

Kadapa district recorded about 4136 cases (3.5) \% of total cases and highest cases recorded in 2010 (1654 cases) followed by 2011 (1160 cases), 2012 (668 cases), 2014 (407 cases) and 2013 (247 cases) and showing decreasing trend in cases.

West Godavari district recorded about 3680 cases $(3.1 \%)$ of the total cases and highest number of cases recorded in 2011 (1199 
cases), followed by 2014 (987 cases), 2013 (692 cases), 2012 (436 cases), and 2010 (366 cases), and showing increasing trend of malaria cases.

Guntur district recorded about 2374 cases (2\%) of the total cases and highest number of cases recorded in 2012 (526 cases), followed by 2013 (498 cases), 2011 (493 cases), 2010 (429 cases), and 2014 (428 cases) and maintaining more or less same number of cases in the study period.

Anantapur district recorded about 2015 cases $(1.7 \%$ )of the total cases and highest number of cases recorded in 2011 (538 cases) followed by 2014 (515 cases), 2012 (372 cases), 2010 (368 cases), and 2013 (222 cases) and showing increasing trend of cases in the study period.

Chittor district recorded about 1100 cases $(0.9 \%$ of total cases) and highest number of cases recorded in 2011 (316 cases) followed by 2012 ( 277 cases), 2010 (251 cases), 2013 (148 cases), 2014 (108 cases) and showing decreasing trend of cases during the study period.

Kurnool district recorded about 1082 cases $(0.9 \%$ of total cases) and highest number of cases recorded in 2010 (279 cases) followed by 2011 (265 cases), 2012 (233 cases), 2014 ( 155 cases), and 2013 (150 cases) and showing decreasing trend of cases during the study period.

Nellore district recorded about 741 cases $(0.6 \%$ of the total cases) and highest number of cases recorded in 2014 (229 cases) followed by 2013 (179 cases), 2011 (143 cases), 2010 (117 cases) and 2013 (73 cases) and showing increasing trend of malaria cases.

\section{2(b) Temporal distribution of malaria cases during 2015 - 2019 period.}

It can be observed from the table no-1 that, about 74,771 malaria cases recorded during 2015 - 2019 period in the study region. About $48.3 \%$ of the total cases of the region recorded in North coastal Andhra region followed by central Coastal Andhra region $(44.3 \%)$ and Rayalaseema region $(7.3 \%)$.

Regarding changes in distribution of malaria cases according to districts, Visakhapatnam district recorded about 24,885 (33.2\%) of the total cases recorded during 2015- 2019 period in which highest number of cases recorded in 2015 (1. 197 cases) followed by 2016 (6479 cases), 2017 (4836 cases), 2018 (2252 cases) and 2019 (1121 cases) and showing decreasing trend of cases during the study period.

East Godavari district recorded about 24,373 cases (32.5\%) in which highest number of cases recorded in 2016 (9061 cases) followed by 2015 (6806 cases), 2017 (5995 cases), 2018 (1865 cases), and 2019 (646 cases) and showing decreasing trend of cases during study period.

Vizianagaram district recorded about 8444 cases (11.2\%) in which highest number of cases recorded in 2015 (3241 cases) followed by 2016 (2939 cases), 2017 (1835 cases), 2018 (305 cases), 2019 (124 cases) and showing decreasing trend of cases during the study period.

Srikakulam district recorded about 2817 cases $(3.7 \%$ of the total cases) in which highest number of cases recorded in 2015 (1143 cases) followed by 2016 (693 cases), 2017 (592 cases), 2018 (264 cases), and 2019 (125 cases) and showing decreasing trend of cases during the study period.

West Godavari district recorded about 2270 cases $(3 \%)$ of the total cases in which highest number of cases recorded in 2016 (730 cases) followed by 2015 (682 cases), 2017 (504 cases), 2018 (209 cases) and 2019 (145 cases) and showing decreasing trend of cases during the study period.

Guntur district recorded about 2785 cases $(3.7 \%)$ of total cases in which highest number of cases recorded in 2017 (962 cases) followed by 2019 (621 cases), 2018 (420 cases), 2015 (413 cases), 2016 (369 cases) and showing increasing trend of cases.

Anantapur district recorded about 2072 cases $(2.7 \%)$ of total cases in which highest number of cases recorded in 2016 (757 cases) followed by 2015 (559 cases), 2017 (496 cases), 2018 (186 cases), 2019 (74 cases) and showing decreasing trend of cases during the study period.

Kadapa district recorded about 2030 cases $(2.7 \%)$ of total cases in which highest number of cases recorded in 2016 (866 cases) followed by 2017 (521 cases), 2015 (352 cases), 2018 (204 cases), and 2019 (87 cases) and showing decreasing trend of cases during the study period.

Krishna district recorded about 1939 cases $(2.5 \%)$ of total cases in which number of cases recorded in 2016 (704 cases) followed by 2017 (666 cases), 2015 (521 cases), 2018 (27 cases), and 2019 (21 cases) and showing decreasing trend of cases.

Prakasam district recorded about 1245 cases (1.6\%) of total cases in which highest number of cases in 2015 (466 cases) followed by 2016 (305 cases), 2017 (262 cases), 2018 (152 cases), 2019 (60 cases) and showing decreasing trend of cases during the study period.

Kurnool district recorded about 1016 cases (1.3\%) of total cases in which highest number of cases recorded in 2016 (420 cases) followed by 2015 (402 cases), 2017 (91 cases), 2018 (65 cases), 2019 (38 cases) and showing decreasing trend of cases.

Fig no.4 (a) Temporal changes of malaria cases during 2010 - $2014 \& 2015$ - 2019 period $\quad$ according to districts. 

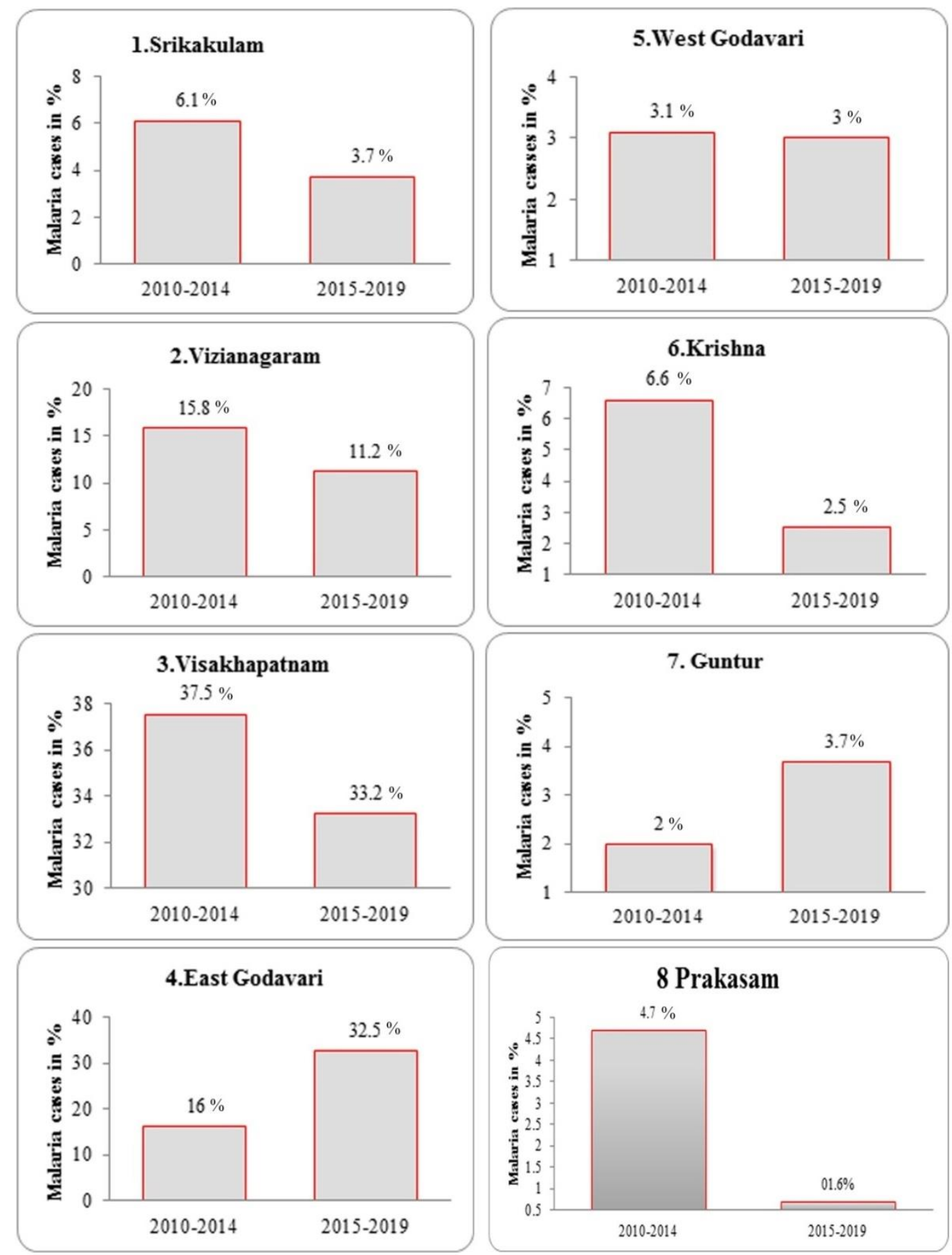

Source: Compiled and prepared by author

Fig no.4 (b) Temporal changes of malaria cases during 2010 - 2014 \& 2015 - 2019 period according to districts. 
9 Nellore/ Pottisriramulu district
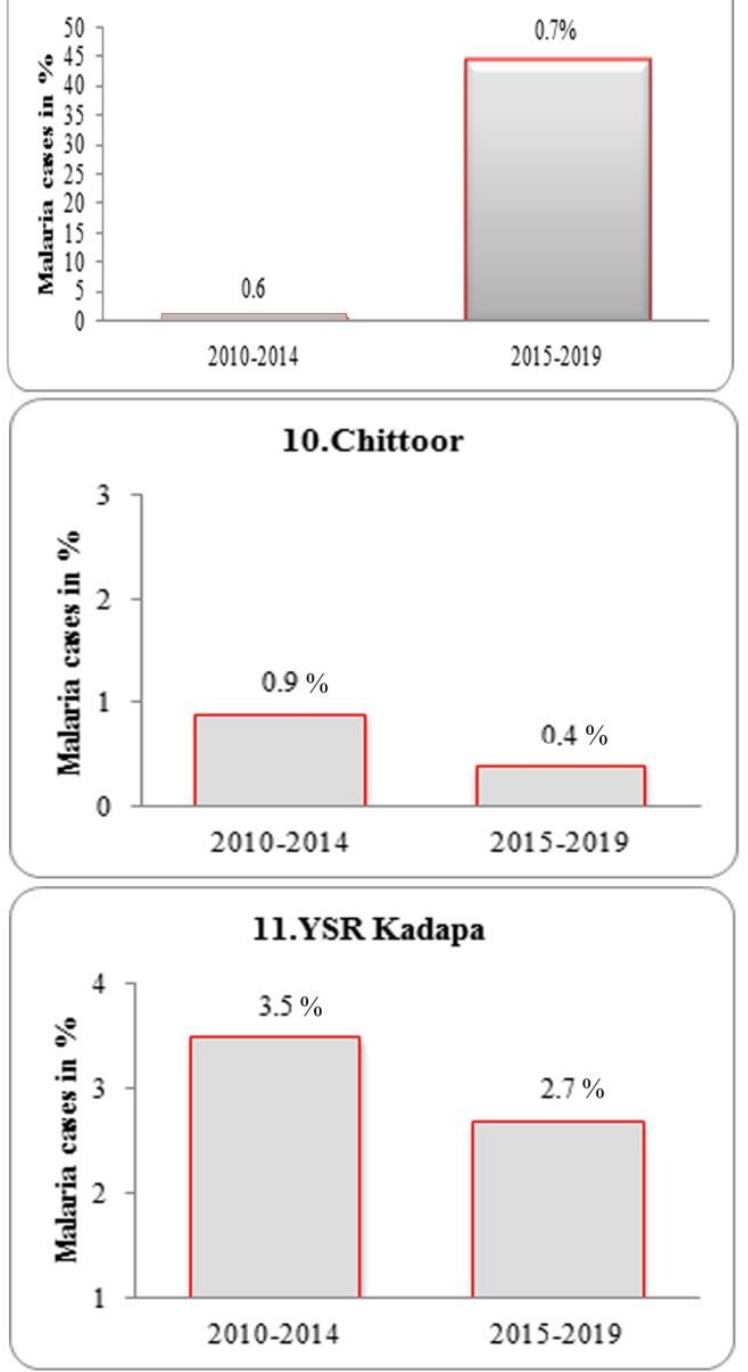

12.Anantapur

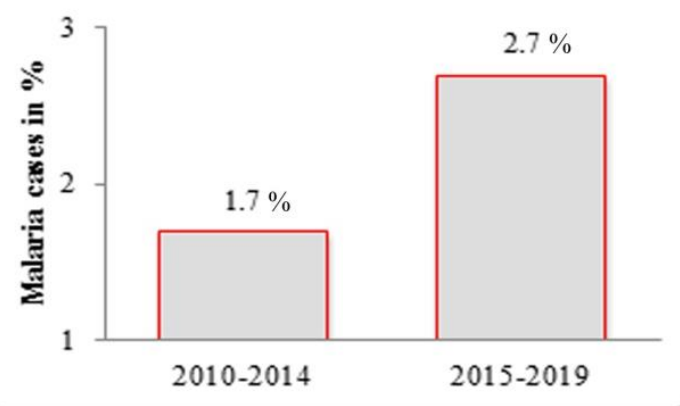

13 Kurnool

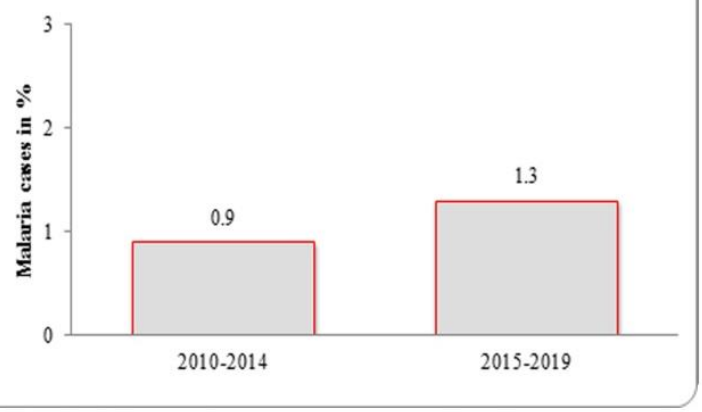

Source: Compiled and prepared by author

Nellore district recorded about 541 cases $(0.7 \%)$ of total cases in which highest number of cases recorded in 2015 (186 cases) followed by 2016 (149 cases), 2017 (125 cases), 2018 (47 cases), 2019 (34 cases), and showing decreasing trend of cases during the study period.

Chittor district recorded about 354 cases $(0.4 \%)$ of total cases in which highest number of cases recorded in 2016 (141 cases) followed by 2017 (87 cases), 2018 (44 cases), 2019 (8 cases) and showing decreasing trend of cases during the study period.

\section{2(c) Temporal Changes in distribution of malaria cases during 2010 - $2014 \&$} area.

Changes in malaria cases during $2010-2014$ \& $2015-2019$ period in the study area is presented in fig no:3 and table no.1. This figure shows that about 1,90,895 malaria cases recorded during 2010 - 2019 period in the study region. Regarding changes in distribution of malaria cases at regional level, about $59.5 \%$ of total malaria cases recorded during 2010 - 2014 period in north coastal Andhra region which reduced to $48.3 \%$ cases during 2015 - 2019 period, followed by central coastal Andhra region which recorded $33.2 \%$ of malaria cases during 2010-2014 period and it increased to $44.3 \%$ of the total cases during 2015-2019 period. Lowest percentage of malaria cases, about $7.1 \%$ recorded in Rayalaseema region during $2010-2014$ period which marginally increased to $7.3 \%$ during $2015-2019$ period.

Table no. 1 also showing that, highest decrease in malaria cases noticed in North coastal Andhra region (-47.7\%) followed by Rayalaseema region (-34.3\%) and lowest decrease in malaria cases noticed in central coastal Andhra region (-10\%) according to physical regions. Further, the entire study region showing decrease $(-35.6 \%)$ in malaria cases during the entire study period( $2010-2014 \& 2015-2019)$.

Regarding changes in distribution of malaria cases according to districts, highest decrease in malaria cases recorded in Prakasam district (-77.2\%), followed by Krishna district (74.7\%), Chittor district (-67.8\%), Srikakulam district (-60.6\%), Vizianagaram district $(-54.1 \%)$, Kadapa district $(-50.9 \%)$, Visakhapatnam distric (-43\%), Guntur district (-17.3\%), Kurnool 
district (-6\%), and lowest decrease of cases noticed in Anantapur district $(-2.8 \%)$. The study reveals that, total numbers of malaria cases recorded during 2015 - 2019 period are less than $2010-$ 2014 period and showing decreasing trend of malaria cases over the study period.

\section{5 (a) Spatial distribution of malaria cases recorded during} 2010 to 2019 period in the study area.

Regarding spatial distribution of malaria cases about 1 , 90,895 cases recorded during 2010- 2019 period in the study region (13 districts). Highest percentage of about $35.9 \%$ of the total malaria cases recorded in Visakhapatnam followed by East Godavari district (22.5\%), Vizianagaram district (14.1\% cases), Srikakulam district (5.2\% cases) Krishna district (5\% cases), Prakasam district ( $3.5 \%$ cases ), Kadapa district (3.2\% cases), west Godavari district (3.1\% cases), Guntur district (2.7\% cases), Anantapur district ( $2.1 \%$ cases), Karnool district (1.1\% cases), Chittor district ( $0.8 \%$ cases), Nellore district ( $0.7 \%$ cases ). Further according to regions about $55.2 \%$ of the total malaria cases recorded in north coastal Andhra region, followed by central coastal Andhra region (37.6\%) and Rayaseema (7.2\%) region.

5 (b) Spatial changes in the distribution of malaria cases during 2010 to 2019 period according to districts in the study area: To study spatial changes, the total number of malaria cases are divided into 5 categories.(1) less than 1000 malaria cases considered as very low cases category.(2) between 1001 to 2000 malaria cases, considered as low cases category. (3) between 2001 to 4000 malaria cases, considered as medium cases category.(4) between 4001 to 8000 malaria cases, considered as high malarial cases category. (5) between 8001 to 13,000 malaria cases, considered as very high cases category.

In this section spatial changes of malaria disease are examined according to districts during 2010-2019 period. About 26,725 malaria cases recorded during 2010 in the study area (13 districts of A.P) in which about $45 \%$ cases recorded in Visakhapatnam district (12,815 cases) and recorded under very high cases category. Krishna district (2757 cases), East Godavari district(2414) and Vizianagaram district (2396 cases) , Kadapa district (1654 cases), Prakasam district (1590 cases) and Srikakulam district (1289 cases) recorded under low malarial cases category where as Guntur district (429 cases), Anantapur district (368 cases), West Godavari district (366 cases), Kurnool district (279 cases), chittor(251) and Nellore district (117 cases) recorded under very low cases category.

In the year 2011 about 30,199 cases recorded which was about $13 \%$ more cases than 2010 year cases. Highest about $30 \%$ of the total malaria cases recorded in visakhapatnam district.
Visakhapatnam district (8977 cases),Vizianagaram district (5449 cases) and East Godavari district (4760 cases) recorded under high cases category. Srikakulam district (2760 cases), and Krishna district (2339 cases) recorded under medium cases category. Prakasam district (1800 cases), West Godavari district (1199 cases), Kadapa district (1160 cases) recorded under low cases category. Anantapur district (538 cases) recorded under very low cases category and Guntur district (493 cases), Chittor district (316 cases), Kurnool district (265 cases)Nellor district (143 cases) recorded under very low cases category.

In the year 2012 about 21,772 cases recorded which was about $28 \%$ less cases than 2011 year cases. Highest about $34 \%$ of the total malaria cases recorded in Visakhapatnam district. Visakhapatnam district (7474 cases) and Vizianagaram district (4992 cases) and recorded under high cases category. East Godavari district (2750 cases) recorded under medium cases category. Krishna district (1585 cases) and Srikakulam district (1424 cases) recorded under low cases category. Prakasam district (962 cases) Kadapa district (668 cases) Guntur district (526 cases) west Godavari district (436 cases), Anantapur district (372 cases), Chittor district (277 cases), Kurnool district (233 cases), Nellore district (73 cases) recorded under very low cases category.

In the year 2013 about 1635 cases recorded which was about $25 \%$ less cases than 2012 year cases. Highest about $36 \%$ of the total cases recorded in Visakhapatnam district. Visakhapatnam district (5950 cases) recorded under high cases category. East Godavari district (3460 cases) and Vizianagaram district (2808 cases) recorded under medium cases category. Srikakulam district (774 cases), west Godavari district (692 cases), Prakasam district (631 cases), Krishan district (592 cases) Guntur district (498 cases), Kadapa district (247 cases), Anantapur district (222 cases), Nellore district (179 cases), Kurnool district (150 cases) Chittor district (148 cases) recorded under very low cases category.

In the year 2014 about 21,077 cases recorded which was about $29 \%$ more cases than 2013 year cases. Highest about $40 \%$ of the total cases recorded in Visakhapatnam district. Visakhapatnam district (8410 cases) and recorded under very high cases category. East Godavari district (5246 cases) recorded under high cases category. Vizyanagaram district (2778 cases) recorded under medium cases category. west Godavari district (987 cases), Srikakulam district (903 cases), Anantapur district (515 cases), Prakasam district (499 cases), Guntur district (428 cases), Kurnool district (155 cases), Chittor district (108 cases) recorded under very low cases category.

Fig No.5. (a) Spatial changes in distribution of malaria cases during 2010-2019 according to districts. 

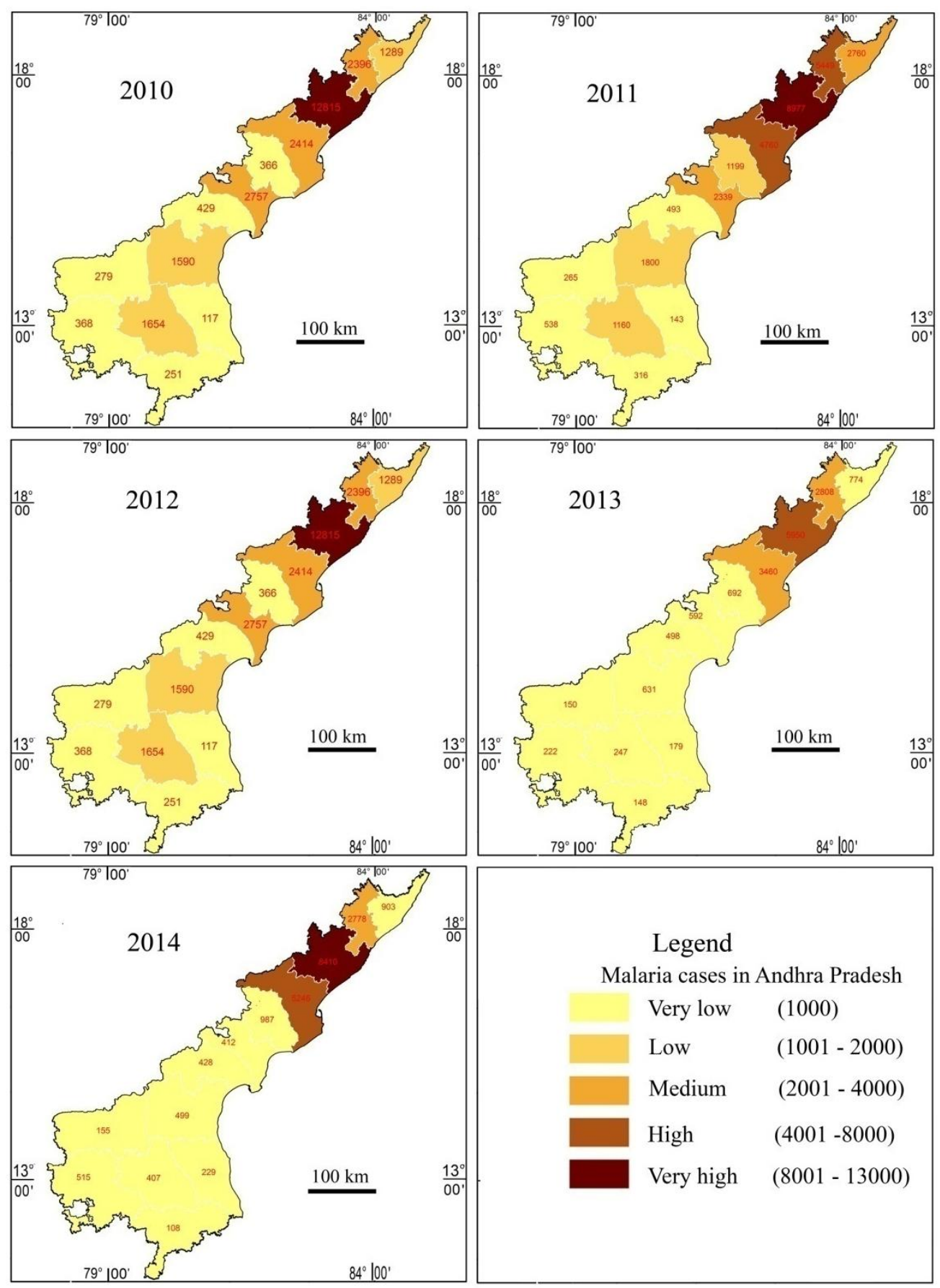

Source: Compiled and prepared by author

Fig No.5. (b) Spatial changes in distribution of malaria cases during 2010-2019 according to districts. 


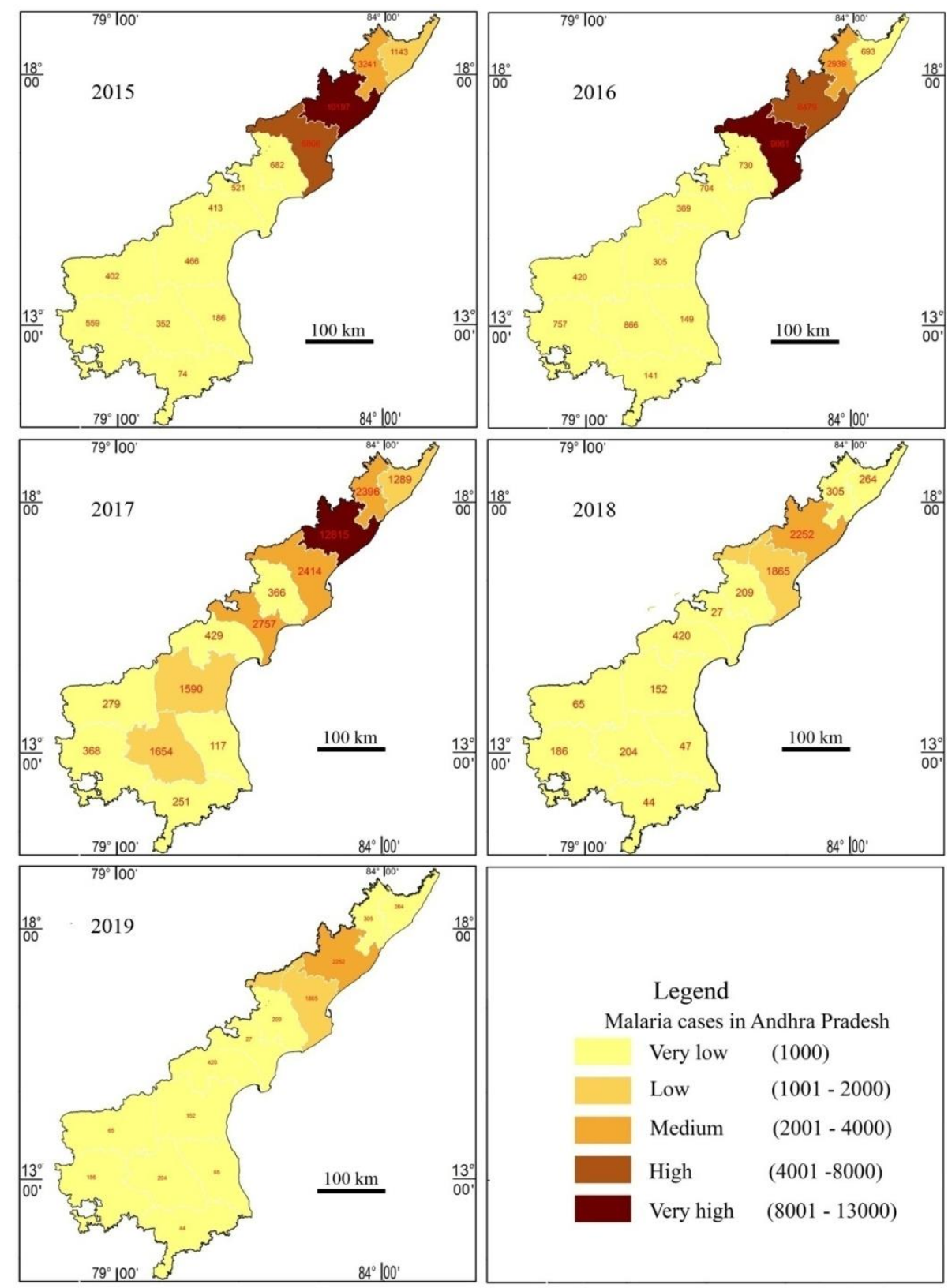

Source: Compiled and prepared by author

In the year 2015, about 25,042 cases recorded which was about $19 \%$ more cases than 2014 year cases. Highest about $41 \%$ of the total cases recorded in Visakhapatnam district. Visakhapatnam district (10,197 cases) recorded under very high cases category. East Godavari district (6806 cases) recorded under high cases category. Vizianagaram district (3241 cases) recorded under medium cases category. Srikakulam district (1143 cases) recorded under low cases category. West Godavari district (682 cases), Anantapur district (559 cases), Krishana district (521 cases), recorded under very low cases category. Whereas Prakasam district (466 cases), Guntur district (413 cases), Kurnool district (402 cases), Kadapa district (352 cases), Nellore district (186 cases),Chittor district (74 cases) recorded under very low cases category.

In the year 2016, about 23,613 cases recorded which was $5 \%$ less cases than 2015year cases. Highest about 38\% of the total cases recorded in East Godavari district. East Godavari district (9061 cases) recorded under very high cases category. Visakhapatnam district (6479 cases) recorded under high cases category. Vizianagaram district (2939 cases) recorded under medium cases category. Kadapa district (866 cases), Anantapur district (757 cases), west Godavari district (730 cases), Krishna district (704 cases), Srikakulam district (693 cases) recorded under very low cases category where as Kurnool district (420 cases), Guntur district (369 cases), Prakasam district (305 cases), Nellore district (149 cases), Chittor district (141 cases) recorded under very low cases category.

In the year 2017 about 16972 cases recorded which was about -28\% less cases than 2015 year. East Godavari district (5995cases) and Visakhapatnam district(4836cases) were recorded under high cases category. Vizianagaram district (1835 cases)recorded under low cases category. Guntur(962 cases), 
Krishna district (666 cases), Srikakulam district(592 cases)Kadapa(521 cases) West Godavari district(504 cases),Anantapur (496 cases),prakasam district (262 cases), Nellore (125 cases),Karnool(91 cases),Chittor (87 cases) recorde under very low cases category.

In the year2018 about 6040 cases recorded which was about-64\% less cases than 2017 year cases. Highest about $37 \%$ of the total cases recorded in Visakhapatnam district. Visakhapatnam district (2252 cases) recorded under medium cases category medium cases category.East Godavari district(1865 cases) recorded under low cases category. Guntur(420 cases),Vzianagaram district (305 cases),Srikakulam district (264 cases),West Godavari district (209 cases)Kadapa (204 cases),Anantapuram district(186 cases), Prakasam district (152 cases), Karnool district(65 cases),Nellore district (47 cases),Chittor district (44 cases) and Krishna district (27 cases) recorded under low cases category.

In the year 2019 about 3104 malaria cases recorded which was about $-48 \%$ less cases than 2018 year cases.Highest about $36 \%$ of total cases recorded in Visakhapatnam district. Visakhapatnam district (1121 cases) recorded under low cases category, whereas East Godavari district(646 cases),Guntur district(62 cases), West Godavari district(145 cases),Srikakulam district(125 cases),Vizianagaram district(124 cases),Kadapa (87 cases),Anantapur $\operatorname{district}(74 \quad$ cases),Prakasam district(60 cases),karnool district(38 cases),Nellore district(34 cases),Krishna district(21 cases), Chittor district( 8 cases) recorded under very low cases category.

\section{CONSLUSION:}

From the above discussion it is observed that, more number of malaria cases recorded in north coastal Andhra region followed by central coastal region and Rayalaseema region during $2010-$ 2014 period and also during 2015 - 2019 period according physical regions. Regarding changes in malaria cases, highest decrease in cases recorded in north coastal Andhra region followed by Rayalaseema region and central coastal Andhra region. During 2010-2019 period. Regarding malaria cases according to district highest number of cases recorded in Visakhapatnam district followed by east Godavari district , Vizianagaram district, Srikakulam district, Krishana district, Prakasam district, west Godavari district, Kadapa district, Guntur district, Anantapur district, Karnool district, Chittor district, where as highest decrease of cases recorded in Prakasam district followed by, Krishna district, Chittor district, Srikakulam district, Vizianagaram district, Kadapa district, Visakhapatnam district, east Godavari district, Nellore district, Guntur district, Kurnool district, and Anantapur. Further, it is also observed that, the number of malaria cases are gradually decreasing over the study period, may be because the control measures taken by the authorities are showing positive results .

\section{REFERENCES}

[1] Bhati PG, Malviya VS, Kant R, Srivastava HC, Sharma SK, Sharma VP. Socio-economic aspects of malaria in Kheda District, Gujarat. Indian $\mathbf{J}$ Malariol.( 1996);33:200-208. [PubMed]
[2] Choudhury DS, Sharma VP, Bhalla SC, Agarwal SS, Das SK. Malaria prevalence in patients attending primary health centers in ten districts of Uttar Pradesh. Indian J Malariol.( 1987);24:79 -83. [PubMed]

[3] Das NG, Baruah I, Kamal S, Sarkar PK, Das SC, Santhanam K. An epidemiological and Entomological investigation on malaria outbreak at Tamalpur PHC, Assam. Indian J Malariol.( 1997);34:164-170. [PubMed]

[4] Dev V, Sharma VP. Persistent transmission of malaria in Sonapur PHC, Kamrup district,

[5] Assam. J Parasitic Dis.(1995);19:65-68.

[6] Dutta P, Khan AM, Mahanta J. Problem of malaria in relation to Sociocultural diversity in some ethnic communities of Assam and Arunachal Pradesh. J Parasitic Dis.( 1999);23:101-104.

[7] Mathur KK, Harpalani G, Kalra NL, Murthy GGK, Narasimham MVVL. Epidemic of malaria in Barmer District (Thar Desert) of Rajasthan during 1990. Indian J Malariol.( 1992);29:1-10. [PubMed]

[8] Malhotra MS, Shukla RP, Sharma VP. Studies on the incidence of malaria in Gadarpur town of terrain, Distt. Nainital, UP Indian J Malariol.( 1985);22:57-60. [PubMed]

[9] Prakash A, Mohapatra PK, Bhattacharyya DR, Doloi P, Ma-hanta J. Changing malaria endemicity-a village based study in Sonitpur, Assam. J Com Dis. (1997);29:175-178. [PubMed]

[10] Shukla RP, Pandey AC, Mathur A. Investigations of malaria outbreak in Rajasthan. Indian J Malariol.( 1995);32:119-128. [PubMed]

[11] Srivastava HC, Kant R, Bhatt RM, Sharma SK, Sharma VP. Epidemiological observations on malaria in villages of Buhari PHC, Surat, Gujarat. Indian J Malariol.( 1995);32:140-152. [PubMed]

[12] Sharma VP. Re-emergence of malaria in India. Indian $\mathrm{J}$ Med Res.(1996);103:26-45. [PubMed]

[13] Sharma VP. Continuing challenge of malaria in India. CurrSci( 2012); 102: 678-82.

[14] Singh N, Singh OP, Sharma VP. Dynamics of malaria transmission in forested and deforested region of Mandla district, Central India, Madhya Pradesh. J Am MosqCont Assoc.( 1996);12:225-34. [PubMed] [Google Scholar]

[15] Shukla MM, Singh N, Singh MP, Tejwani BM, Srivastava DK, Sharma VP. Cerebral malaria in Jabalpur, India. Indian J Malariol.(1995);32:70-75. [PubMed]

[16] Singh N, Shukla MM, Sharma VP. Epidemiology of malaria in pregnancy in Central India. Bull World Health Organ. (1999);77:567-572. [PMC free article] [PubMed]

[17] Sharma VP, Uprety HC, Srivastava PK, Chandrahas RK. Studies on malaria transmission in hutments of Delhi. Indian J Malariol.( 1985);22:77-84. [PubMed]

[18] WHO. World Malaria Report( 2017); World Health Organization: Geneve, Switzerland, 2017

[19] WHO: Manual on practical entomology in malaria part 1: vector bionomicts and organization of anti-malarial activities.( 1975), Geneva: World Health Organization

[20] World Health Organization (2007) Estimation of malaria disease burden in India. World

[21] Health Organization, Regional office for South-East Asia 2007.

[22] Yadav RS, Ghosh SK, Chand SK, Kumar A. Prevalence of malaria and economic loss in two major iron ore mines in Sundergarh district, Orissa. Indian J Malariol. (1991);28:105-113. [PubMed]

\section{AUTHORS}

First Author -A.Raju, Resarch scholor, Department of Geography, Andhra University, Visakhapanam, (AP). Second Author - Prof. T.V.Krishna, Department of Geography, Andhra University, Visakhapanam, (AP). 
